\title{
On the generality of habitat distribution models: a case study of capercaillie in three Swiss regions
}

\author{
Roland F. Graf, Kurt Bollmann, Sébastien Sachot, Werner Suter and Harald Bugmann
}

\begin{abstract}
Graf, R. F., Bollmann, K., Sachot, S., Suter, W. and Bugmann, H. 2006. On the generality of habitat distribution models: a case study of capercaillie in three Swiss regions. - Ecography 29: 319-328.
\end{abstract}

\begin{abstract}
Predictive habitat distribution models are normally assumed to sacrifice generality for precision and reality. Nevertheless, such models are often applied to predict the distribution of a species outside the area for which the model has been calibrated. We investigated how the geographic extent of the data used for calibration influenced the performance of habitat distribution models applied on independent data. We took a multi-scale logistic regression approach by varying the grain size to develop six habitat models for capercaillie Tetrao urogallus in Switzerland: three regional models, for the northern Pre-Alps, eastern Central Alps and Jura mountains, respectively, and three pooled models, each using data from two of the three regions. The six models were validated with data from the region(s) not used for model building. We used Cohen's Kappa and the area under the receiver operating characteristics curve as accuracy measures. The regional models performed well in the region where they had been calibrated, but poorly to moderately well in the other regions. The pooled models classified almost as well in their calibration regions as the corresponding regional models, but generally better when validated on data from the independent region. Hence, models built with data from single regions provide less certain predictions of species' distributions in other regions. We recommend building more general models using data pooled from several regions, when the aim is to predict species' distributions in independent regions.
\end{abstract}

R. F. Graf (roland.graf@alumni.ethz.ch), K. Bollmann and W. Suter, Swiss Federal Research Inst. WSL, Zürcherstrasse 111, CH-8903 Birmensdorf, Switzerland. - S. Sachot, Centre de conservation de la faune et de la nature du canton de Vaud, Chemin $d u$ Marquisat 1, CH-1025 St-Sulpice, Switzerland. - H. Bugmann, Forest Ecology, Dept of Environmental Sciences, Swiss Federal Inst. of Technology Zürich ETH, CH-8092 Zürich, Switzerland. (Present address of R. F. G.: UFZ - Centre for Environmental Research Leipzig-Halle, Dept of Ecological Modelling, Permoserstr. 15, D-04318 Leipzig, Germany.)

Predictive habitat distribution models have become an established instrument for describing species-habitat relationships (Guisan and Zimmermann 2000, Rushton et al. 2004). This development has been furthered by new statistical techniques, increasing availability of data on species distribution and land use, and new computer tools for efficiently working with them (Guisan and Zimmermann 2000). Statistical models often contain surrogate variables to predict the occurrence of a species, wherefore they are generally assumed to sacrifice generality for precision and reality (Sharpe 1990). Nevertheless, the results are often meant to apply elsewhere, e.g. for predicting potential habitats or the distribution of a species in areas with sparse data (e.g. Mladenoff and Sickley 1998, Mace et al. 1999). In addition, many studies of species-habitat relationships use a small

Accepted 8 November 2005 
number of sites located in the same geographical area (Whittingham et al. 2003). Even when data are collected from a large range of geographical locations, the results are often pooled as one data set (e.g. Carroll et al. 1999, Corsi et al. 1999) without consideration of regional differences.

Habitat models for predicting species distributions should be evaluated carefully. For studies carried out in homogenous regions, Fielding and Bell (1997) recommended a data-partitioning technique such as $\mathrm{k}$-fold partitioning or jack-knife cross-validation. However, such approaches have limited value for assessing model credibility and applicability, because they do not evaluate the model outside its calibration range (Guisan and Zimmermann 2000). The most appropriate way of evaluating predictive habitat models would be to apply them on independent data sets from geographically distinct regions (Manel et al. 1999, Guisan and Zimmermann 2000). However, this has rarely been done due to lack of corresponding evaluation data (but cf. Fielding and Haworth 1995, Rodriguez and Andren 1999, Morris et al. 2001, Zabel et al. 2003).

The capercaillie Tetrao urogallus, Tetraonidae, Aves is a large forest grouse species with specialized habitat preferences (e.g. Schroth 1992, Sjöberg 1996) and extensive spatial requirements (Storch 1995), and is thus highly susceptible to habitat and landscape changes. Capercaillie populations are declining throughout most of their central European range (e.g. Klaus et al. 1986, Storch 2000b) including Switzerland (Mollet et al. 2003), as loss and fragmentation of suitable habitats have split populations into smaller units that are only loosely connected or even completely isolated.

At the forest stand scale, the habitat requirements of capercaillie have been studied intensively throughout its distribution range in Europe (e.g. Klaus et al. 1985, Leclercq 1987, Gjerde 1991, Picozzi et al. 1992, Storch 1993a, Sjöberg 1996, Bollmann et al. 2005). Some habitat features are common to most distribution areas. Capercaillie requires open-structured coniferous or mixed forest (Klaus et al. 1986) with a lush field layer (Picozzi et al. 1992, Schroth 1992, Storch 1994, Sjöberg 1996) ideally dominated by bilberry Vaccinium myrtillus, (Klaus et al. 1985, Rolstad 1988, Schroth 1992, Storch 1993a, Baines et al. 2004).

Conservation actions have not been able to slow down the population decline, despite the good knowledge base on small-scale habitat preferences. Therefore, remedy is now sought at larger spatial scales. Telemetry studies in Scandinavia and in central Europe have revealed that spatial requirements of capercaillie are extensive (Wegge and Larsen 1987, Storch 1995). Further, they have shown that capercaillie populations are sensitive to the spatial configuration of preferred habitats and to forest fragmentation (Rolstad and Wegge 1989, Wegge et al. 1992). Recent work has supported the notion that capercaillie populations are strongly driven by landscape-scale processes (Storch 1997, Kurki et al. 2000). These processes, however, have insufficiently been addressed in predictive habitat modelling designed for large areas. Most habitat models presently available for capercaillie do not include spatial variables (Storch 2002), do not address the effect of spatial grain size explicitly (Sachot et al. 2003, Sachot and Perrin 2004), or do not include different grain sizes in a single statistical model (Suchant 2002). None of the previous studies addressed the effect of geographic extent by studying habitat-relationships in different regions or by validating resulting models outside the calibration region. Thus, uncovering larger-scale habitat relationships is still an important research need in those regions where the species is endangered (Storch 2000a), and analyses should be conducted at multiple scales (Keppie and Kierstead 2003).

In this study, we investigated how the data used for model calibration (geographic extent) influence the performance of habitat models on independent evaluation data (generality). We developed three separate habitat models for capercaillie for three regions that differ strongly in terms of climate, landscape structure and land use. These regional models were compared with three models each built with pooled data from two of the three regions. To assess their precision and generality the six models were validated with data from the region(s) not used for model building.

\section{Methods}

\section{Study area and species data}

In Switzerland, capercaillie occurs in three mountain regions: Jura, northern Pre-Alps, and eastern Central Alps (Fig. 1). These regions differ in terms of climate, topography and geology, forest distribution and human land use. In the eastern Central Alps (600-3500 m a.s.1.), the climate is continental with a relatively low precipitation rate $\left(800-2000 \mathrm{~mm} \mathrm{yr}^{-1}\right)$, cold winters but warm and dry summers. Under these conditions, the upper natural tree-line is at ca $2300 \mathrm{~m}$ a.s.l. Large contiguous and mostly conifer-dominated forests spread along the valley slopes. Generally, human population density and tourist pressure are low, except for some areas that are used intensively for winter and summer sport activities.

The northern Pre-Alps (400-2800 m a.s.1.) are characterized by a more atlantic climate with cold-temperate winters and wet summer months which limits the upper tree-line to ca $2000 \mathrm{~m}$ a.s.l. High precipitation (2000$3000 \mathrm{~mm} \mathrm{yr}^{-1}$ ) and often impervious soils have allowed mires to develop in many areas. Along their fringes, forest stands are naturally open and diversely structured. They have thus little commercial value but are favoured by capercaillie and other woodland grouse species. The 
Fig. 1. Map of Switzerland with the three study regions and their use for modelling. The regions of the northern PreAlps and the eastern Central do not represent the whole capercaillie distribution in Switzerland. dashed line separates the Alps. The three study regions

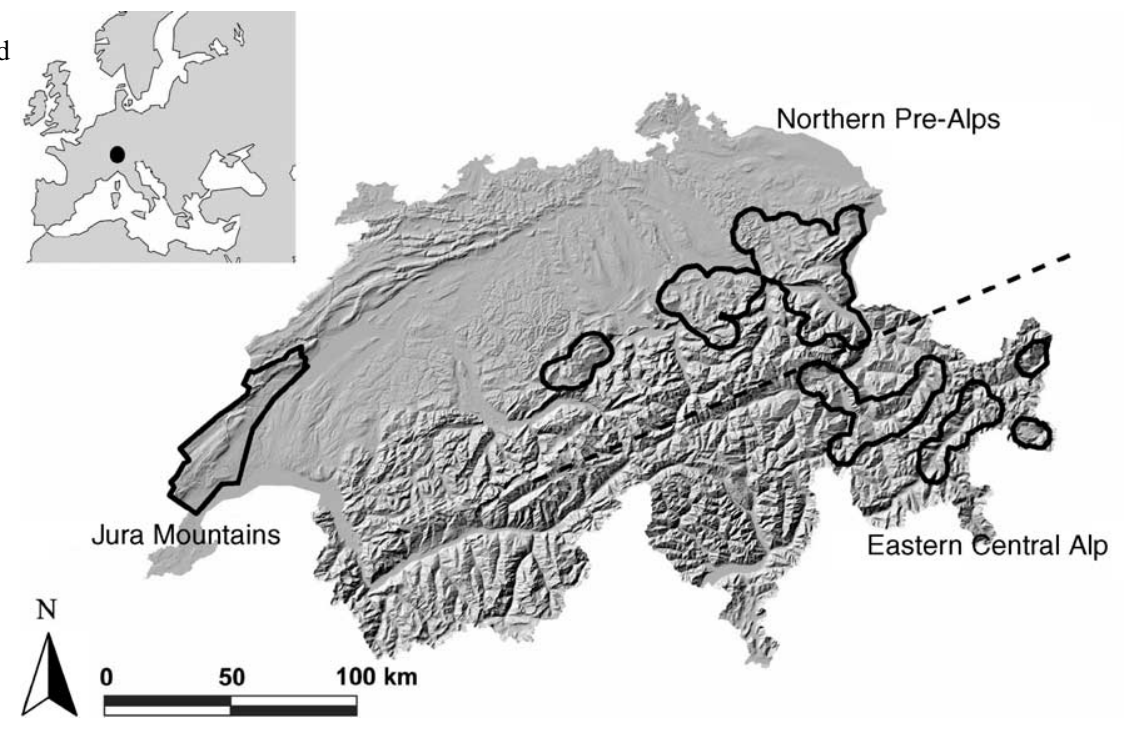

northern Pre-Alps have been strongly altered by farming practices that depend mostly on livestock resulting in a patchy pattern of forest and pasture over large areas. The northern Pre-Alps are within a half day's drive of the major Swiss cities, and thus are frequently used for recreation activities, which may lower survival and reproduction rate of capercaillie in some instances.

The Jura Mountains ( $800 \mathrm{~km}^{2}, 400-1700 \mathrm{~m}$ a.s.l.) are a calcareous mountain range in the north-western part of Switzerland, geographically separated from the PreAlps and the Alps by the plateau (width of 30-40 km). The Jura Mountains have an atlantic climate similar to that of the northern Pre-Alps (average precipitation $2000 \mathrm{~mm} \mathrm{yr}^{-1}$ ) but are, in contrast to the other two regions, characterized by gentle slopes and larger, contiguous forest expanses.

We used data from parts of the eastern Central Alps $\left(1700 \mathrm{~km}^{2}, 47^{\circ}-46^{\circ} 50^{\prime} \mathrm{N}\right.$. $\left.9^{\circ} 30^{\prime}-10^{\circ} 30^{\prime} \mathrm{E}\right)$, from the northern Pre-Alps $\left(2800 \mathrm{~km}^{2}, 46^{\circ} 45^{\prime}-47^{\circ} 25^{\prime} \mathrm{N}\right.$. $\left.8^{\circ}-9^{\circ} 30^{\prime} \mathrm{E}\right)$ and from the Jura Mountains $\left(800 \mathrm{~km}^{2}\right.$, $46^{\circ} 20^{\prime}-46^{\circ} 55^{\prime} \mathrm{N}$. $\left.6^{\circ} 10^{\prime}-6^{\circ} 45^{\prime} \mathrm{E}\right)$ for the habitat models (Fig. 1). Capercaillie distribution data originated from our own fieldwork (2000-2003, Pre-Alps and Alps and 1998-2002, Jura Mountains) and from several regional inventories. They include both sightings and indirect evidence of capercaillie presence (faeces, feathers, footprints, etc.). The records stem mainly from late winter and spring surveys, but were supplemented with other data available (records by game wardens, ornithologists, foresters, etc.) from throughout the year. See Graf (2005, Appendix I) and Sachot (2002) for detailed descriptions of the data set on capercaillie occurrence.

We used only presence-absence data, since these tend to better explain habitat relationships of rare species than abundance data (Cushman and McGarigal 2004). Presence-absence data were processed in grid format with cell size of 1 ha, i.e. the same resolution as in most environmental data used for analysis. We defined cells as "presence" if they contained at least one capercaillie record. Not all presence cells were used in the analyses, as their clumped distribution could have led to autocorrelation problems. Therefore, we reduced the number of presence cells, so that the minimum distance between any two presence cells was at least $500 \mathrm{~m}$. Absence cells used in the analysis were a randomly selected subset of cells with a minimum distance of $1 \mathrm{~km}$ to the nearest presence cell, a minimum distance of $500 \mathrm{~m}$ to the nearest absence cell and a maximum distance of $5 \mathrm{~km}$ to the nearest presence cell. The first rule produced a minimum buffer area of ca $3 \mathrm{~km}^{2}$ around all observations, an area that equals about the size of the home range of a capercaillie individual (Rolstad et al. 1988, Storch 1995). By allowing a buffer between presence and absence cells, we also avoided that cells where no record was obtained, but where capercaillie occurred in reality were erroneously classified as absence. The last rule ensured that only those areas were included that are located within a realistic dispersal distance from forest stands actually used by capercaillie (Storch and Segelbacher 2000, Segelbacher et al. 2003). By doing so, we implicitly assumed that habitat suitability was the reason for the absence of capercaillie, rather than large-scale population effects.

\section{Environmental variables}

As we focussed on generality in habitat models, we decided to keep our models simple by using only three predictor variables: proportion of forest, average temperature, and topographic position (Table 1). These variables had been found to be good predictors for 
Table 1. Environmental variables used as independent predictors.

Variable description

Abbreviation Unit

Proportion of forest

Proportion of forest cells available within the moving window around a focal cell; based on a grid data set

$(1=$ forest, $0=$ not forest; cell size $20 \mathrm{~m}$ ) derived from thematic pixel maps (PK25@2004, SWISSTOPO,

DV033594, scale of 1:25000).

Average temperature

Long-term monthly means of average June temperature; spatially interpolated from point data from the

Swiss net of climate stations using a digital elevation model (as described in Zimmermann and Kienast

1999).

Topographic position

Measures the exposure of a location compared to the surrounding terrain; positive values indicate relative

ridges and hilltops, negative values indicate sinks, gullies and valley bottoms (see Zimmermann and Kienast

PFOR

$\%$

1999, Guisan et al. 1999, Zimmermann and Roberts 2001).

capercaillie habitat in Switzerland (cf. Graf et al. 2005) and had also been reported in the literature as having explanatory value for distribution or population dynamics of capercaillie elsewhere. Vegetation type and spatial vegetation patterns influence population density, home range size, mortality and reproductive success of capercaillie (Wegge and Rolstad 1986, Storch 1994, 1995, Kurki et al. 2000, Baines et al. 2004). Local climate is an important factor affecting reproduction of capercaillie, as dry and warm weather in early summer reduces chick mortality (Moss et al. 2001, Summers et al. 2004). Further, there is evidence that capercaillie preferably occur on ridges and upper slopes than in valley bottoms (e.g. Roth and Nievergelt 1975, Suchant 2002).

We prepared the three independent variables in grid format with a cell size of one hectare. With a moving window analysis (ARC/INFO 8.3, ESRI, Redlands CA, USA; focal statistics), we calculated the mean values for a circular neighbourhood of each grid cell for proportion of forest and topographic position. The window size was increased stepwise from 1 ha up to just over 1100 ha, which is about twice the size of a mean home range (Storch 1995). We included 10 window sizes, hereafter called "spatial grain size" (the radius $[100 \mathrm{~m}]$ of the circular analysis window is given in parentheses): 1, 5 (1), 13 (2), 29 (3), 49 (4), 81 (5), 113 (6), 253 (9), 529 (13), and 1129 ha (19). The uneven numbers result from the moving window algorithm that works with entire grid cells. We did not vary spatial grain size for the variable "average temperature" because 1) the data set stems from interpolation of point data and 2) the variable had shown no sensitivity to spatial grain size in earlier analyses.

\section{Statistical modelling}

\section{Modelling procedure}

First, we calculated univariate models for the two predictor variables "proportion of forest" and "topographic position" at each spatial grain size. For the variable "average temperature", we calculated univariate models only at the smallest scale (1 ha). The univariate models provided information on the response and predictive power of each predictor variable and helped us to define the "best" grain size at which a variable explained the highest amount of the variance in capercaillie presence-absence (cf. Graf et al. 2005).

Second, we developed six multivariate models. We calculated a regional model for each of the three regions separately $\left(\mathrm{N}=222 ; \mathrm{N}_{\text {Pres }}=83, \mathrm{~N}_{\mathrm{Abs}}=139\right)$ and three models using pooled data from two of the three regions $\left(\mathrm{N}=444 ; \mathrm{N}_{\text {Pres }}=166, \mathrm{~N}_{\mathrm{Abs}}=278\right)$. All the six models were then evaluated on data from the region(s) not used for model building. The sample size of the presence and absence cells purposefully differed to account for the larger variance in the absence data. For the multivariate models, we used the two variables "proportion of forest" and "topographic position" at the scales at which they explained best in the univariate models (Graf et al. 2005). Thus, we defined the "best" scales for PFOR and TOPO for the three regions and for the three pooled data sets (Pre-Alps/Alps, Pre-Alps/Jura, Alps/Jura) to calculate the multivariate models. For the variable topographic position in the Jura Mountains, we chose a smaller moving window size than the one with the highest explained variance, because the variable is increasingly correlated with average temperature as window size increases. We chose the largest possible moving window size for which Spearman's correlation of the two variables did not exceed a value of 0.7 (cf. Fielding and Haworth 1995).

One might argue that for comparing the generality of habitat models between regions it would have been better to use the independent variables in all models at the same spatial grain size. We tested this alternative approach and calculated six additional models where we entered the three variables at one arbitrarily chosen grain size: proportion of forest at a scale of 256 ha, average temperature and topographic position at 1 ha. The two approaches gave similar results and entailed the same conclusions. Therefore, the results of the alternative approach are not shown. 
To test for spatial dependence of residuals, we calculated Moran's I in R2.0.0 (Ihaka and Gentleman 1996, extensions used: spdep, tripack, maptools) for the first lag. Additionally, we calculated spatial correlograms to detect possible spatial dependence of residuals at higher lags.

\section{Logistic regression}

Logistic regression (Menard 2002, Manly et al. 2002) was applied to all habitat modelling using the software SPSS 11.0 (Chicago, IL, USA). In all multivariate models, we applied a threshold probability of 0.2 for whether a predictor variable was omitted (Hosmer and Lemeshow 2000). In all modelling, we included untransformed variables, as normality is not required and error terms are allowed to have non-Gaussian distributions (Guisan and Zimmermann 2000). By plotting the frequency distribution of the predictor variables for both presence and absence cells, we searched for the type of response. In the case of a unimodal response (average temperature TAVE), the squared predictor variable was also included in the analyses (TAVE ${ }^{2}$ ).

\section{Calibration and validation}

For assessing the model fit, we used R-square Nagelkerke (Nagelkerke 1991), which measures the variance in the dependent variable explained by the independent variables. To evaluate model accuracy, we used measures based on a confusion matrix (Fielding and Bell 1997, Boyce et al. 2002) and calculations were done with SimTest < http://www.wsl.ch/staff/niklaus.zimmermann/ programs/progs $/>$. A confusion matrix contains the predicted and observed presences and absences based on a fitted model. From this matrix, a number of different accuracy measures can be derived. We use the correct classification rate (CCR) and Kappa-statistics (Monserud and Leemans 1992). Kappa measures the actual agreement minus the agreement expected by chance and can take values between 0 (no agreement) and 1 (perfect agreement). We used Kappa both at a threshold of 0.5 (Kappa_05) and at the optimized threshold (Kappa_opt). To determine the optimized threshold, we calculated Kappa for all possible threshold values from 0.01 to 0.99 and considered the threshold to be best at which Kappa attained the highest value. If a model is applied in an area where the species' distribution is poorly known, the threshold can not be optimized. Here, a threshold of 0.5 would be the default choice. Therefore, we considered Kappa_05 to be a particularly important measure. Further, we used the area under the receiver operating characteristics curve (AUC, Deleo 1993) as a measure of overall accuracy that is not dependent upon a particular threshold (Fielding and Bell 1997, Boyce et al. 2002, McPherson et al. 2004). AUC varies between 0 and 1 . A value of 0.8 for the AUC means that for $80 \%$ of the time a random selection from the presence cells will have a predicted score greater than a random selection from the absence cells.

\section{Results}

\section{Univariate analysis}

Each of the three predictor variables had high predictive power in the univariate models $\left(\mathrm{R}_{\mathrm{N}}^{2}>0.3\right)$, except TOPO in the Pre-Alps, TAVE in the Alps and PFOR in the Jura (Table 2). The explained variance of PFOR and TOPO differed markedly among the spatial grain sizes and among the three regions (Fig. 2). The spatial grain sizes at which a variable explained the highest amount of the variance in capercaillie presence-absence were used for the multivariate models (see Methods).

\section{Multivariate analysis}

All six models (Pre-Alps, Alps, Jura, Pre-Alps/Alps, PreAlps/Jura, Alps/Jura) explained a large amount of the variance of the presence-absence pattern $\left(\mathrm{R}_{\mathrm{N}}^{2}>0.70\right)$ and were very successful in predicting capercaillie presenceabsence in the calibration area (CCR_05 $>86$, Kappa_05 $>0.71$; Table 3). When applied outside the calibration region(s), the regional models performed on average weaker (mean AUC $=0.89$, mean Kappa_05 = 0.46) than the models built with pooled data (mean AUC $=0.91$, mean Kappa_05 $=0.54$; Table 3). Even more important may be that the minimum Kappa_05 value is 0.26 (poor prediction) in the regional models and 0.46 (moderate prediction) in the models built with pooled data. Thus, using data from two regions for model calibration reduced the probability of poor prediction in a new region.

In the multivariate models, average temperature (TAVE) and proportion of forest (PFOR) were significant in all six models (Table 4). These two variables also explained much of the variance of capercaillie occurrence in the univariate analyses in all regions (Table 2). The models developed with the pooled data and the regional model for the Pre-Alps contained both TAVE and the squared variable TAVE $^{2}$ and thereby simulated a unimodal response of capercaillie occurrence to average temperature. Topographic position (TOPO) was only significant in models using data from the Alps.

In three cases, model residuals on the first lag were spatially auto-correlated (Moran's I different from 0 at the $5 \%$ significance level). Those models were the ones where the data-set of the central Alps was included. The regional model built with data from the Alps attained the highest (but still low) values (Moran's I $=0.080$, 
Table 2. Univariate logistic regression models of capercaillie occurrence in three Swiss regions: spatial grain size (Scale [ha]); explained variance expressed by R-square Nagelkerke $\left(\mathrm{R}_{\mathrm{N}}^{2}\right)$; type of response to capercaillie occurrence, i.e. linearly positive (pos), linearly negative (neg) or unimodal (uni).

\begin{tabular}{|c|c|c|c|c|c|c|c|c|c|}
\hline \multirow[b]{2}{*}{ Variable } & \multicolumn{3}{|c|}{ Pre-Alps } & \multicolumn{3}{|c|}{ Alps } & \multicolumn{3}{|c|}{ Jura } \\
\hline & Scale & $\mathrm{R}_{\mathrm{N}}^{2}$ & Response & Scale & $\mathrm{R}_{\mathrm{N}}^{2}$ & Response & Scale & $\mathrm{R}_{\mathrm{N}}^{2}$ & Response \\
\hline PFOR & 253 & 0.426 & pos & 81 & 0.701 & pos & 1129 & 0.241 & pos \\
\hline TAVE & 1 & 0.577 & uni & 1 & 0.233 & uni & 1 & 0.763 & neg \\
\hline TOPO & 1129 & 0.162 & pos & 5 & 0.429 & pos & 1129 & 0.459 & pos \\
\hline
\end{tabular}

$\mathrm{p}=0.009$ ), the other coefficients were close to 0 (model for Pre-Alps/Alps, Moran's I $=0.016, \mathrm{p}=0.020$; model for Alps/Jura, Moran's $I=0.036, p=0.038$ ). On the second lag, all Moran's I coefficients were smaller than $0.05)$.

\section{Discussion}

Habitat distribution models often have limited predictive power when applied to other regions (Fielding and Haworth 1995, Corsi et al. 1999, Guisan and Zimmermann 2000, Lawler and Edwards, Jr 2002). The aim of this study was to explore the generality of habitat distribution models for capercaillie using data from three mountainous regions. We found that models calibrated with data from one region had lower predictive success outside the calibration region than models using pooled data from two regions. In the following paragraphs we discuss our results by addressing three main aspects. First, we discuss the structure and general performance of the six habitat models. Second, we evaluate model precision and generality in view of the data used for calibration. Third, the role of direct and indirect (surrogate) predictor variables for model generality is assessed.

\section{The habitat models}

Our habitat models based on three predictor variables explain much of the variance in the large-scale presenceabsence pattern of capercaillie $\left(\mathrm{R}_{\mathrm{N}}^{2}>0.7\right)$. The high model performance may have two major reasons. First, the values of the selected variables discriminate strongly between presence and absence locations thus resulting in good model performance. Second, the rule to define absence locations (minimum distance of $1000 \mathrm{~m}$ to next presence cell; cf. Graf et al. 2005) increases model performance to some albeit limited degree.

The variables "average temperature" and "proportion of forest" that came out significant in all six models have been reported to influence capercaillie occurrence also in other parts of its distribution range. Its need for large and well-connected forests is documented both for central Europe (Storch 1995, Sachot and Perrin 2004) and Scandinavia (Kurki et al. 2000, Linden et al. 2000). Capercaillie also occurs mainly in the temperature zone that allows coniferous forests to grow naturally (Klaus et al. 1986).

Only a few studies, mainly from central Europe, have discussed the role of topography in habitat use of capercaillie (Roth and Nievergelt 1975, Eiberle 1976, Schroth 1992, Suchant 2002). In our study, topographic position was significant in two pooled models (Pre-Alps/ Alps, Alps/Jura) and in the regional model of the Alps. Thus, under certain landscape conditions (alpine topo-

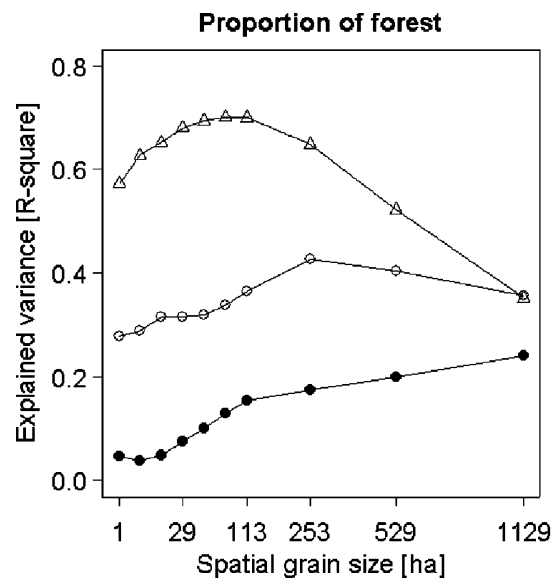

324

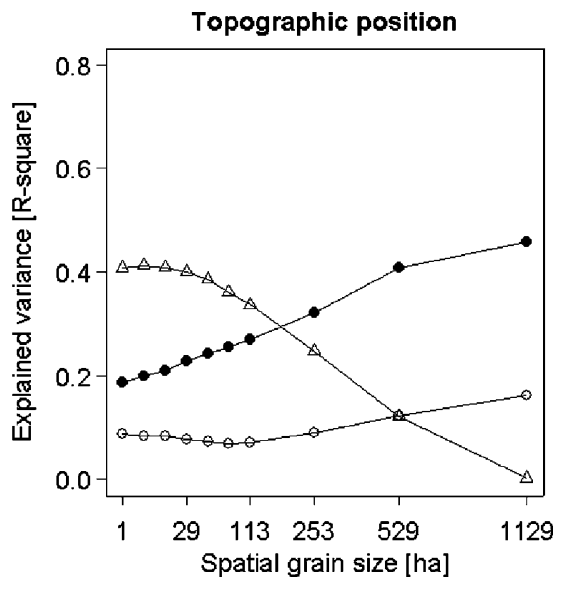

Fig. 2. Explained variance (R-square Nagelkerke) of univariate models as a function of spatial grain size for the two predictor variables "proportion of forest" and "topographic position". The three curves used data from the northern Pre-Alps (empty circles), the eastern Central Alps (triangles) and the Jura Mountains (filled circles). 
Table 3. Accuracy of multivariate capercaillie habitat distribution models built with data from one region (Pre-Alps, Alps, Jura) and with pooled data from two regions (Pre-Alps/Alps, Pre-Alps/Jura, Alps/Jura); sample size in calibration data set (N_calib), R-square Nagelkerke $\left(\mathrm{R}_{\mathrm{N}}^{2}\right)$, Kappa at a threshold of 0.5 (Kappa_05), Kappa at optimized threshold (Kappa_opt), Correct classification rate at a threshold of 0.5 (CCR_05), Area under the ROC-curve (AUC). Bold face indicate validation results against independent data.

\begin{tabular}{|c|c|c|c|c|}
\hline \multirow[b]{2}{*}{ Model } & \multicolumn{4}{|c|}{ Model calibration } \\
\hline & N_Calib & $\mathrm{R}_{\mathrm{N}}^{2}$ & Kappa_05 & CCR_05 \\
\hline $\begin{array}{l}\text { Pre-Alps } \\
\text { Alps } \\
\text { Jura } \\
\text { Pre-Alps/Alps } \\
\text { Pre-Alps/Jura } \\
\text { Alps/Jura }\end{array}$ & $\begin{array}{l}222 \\
222 \\
222 \\
444 \\
444 \\
444\end{array}$ & $\begin{array}{l}0.738 \\
0.845 \\
0.867 \\
0.702 \\
0.702 \\
0.755\end{array}$ & $\begin{array}{l}0.81 \\
0.82 \\
0.86 \\
0.71 \\
0.72 \\
0.77\end{array}$ & $\begin{array}{l}0.91 \\
0.91 \\
0.93 \\
0.86 \\
0.86 \\
0.89\end{array}$ \\
\hline & \multicolumn{4}{|c|}{ Validation on Pre-Alps $(\mathrm{N}=222)$} \\
\hline Model & Kappa_05 & Kappa_opt & CCR_05 & AUC \\
\hline $\begin{array}{l}\text { Pre-Alps } \\
\text { Alps } \\
\text { Jura } \\
\text { Pre-Alps/Alps } \\
\text { Pre-Alps/Jura } \\
\text { Alps/Jura }\end{array}$ & $\begin{array}{l}0.81 \\
0.26 \\
\mathbf{0 . 4 9} \\
0.64 \\
0.65 \\
\mathbf{0 . 4 6}\end{array}$ & $\begin{array}{l}0.81 \\
\mathbf{0 . 5 6} \\
\mathbf{0 . 6 8} \\
0.73 \\
0.75 \\
\mathbf{0 . 7 2}\end{array}$ & $\begin{array}{l}0.91 \\
\mathbf{0 . 7 1} \\
\mathbf{0 . 7 7} \\
0.84 \\
0.84 \\
\mathbf{0 . 7 7}\end{array}$ & $\begin{array}{l}0.95 \\
\mathbf{0 . 8 9} \\
\mathbf{0 . 9 1} \\
0.94 \\
0.94 \\
\mathbf{0 . 9 3}\end{array}$ \\
\hline Alps/Jura & \multicolumn{4}{|c|}{ Validation on Alps $(\mathrm{N}=222)$} \\
\hline Model & Kappa_05 & Kappa_opt & CCR_05 & AUC \\
\hline $\begin{array}{l}\text { Pre-Alps } \\
\text { Alps } \\
\text { Jura } \\
\text { Pre-Alps/Alps } \\
\text { Pre-Alps/Jura } \\
\text { Alps/Jura }\end{array}$ & $\begin{array}{l}\mathbf{0 . 6 5} \\
0.82 \\
\mathbf{0 . 3 9} \\
0.77 \\
\mathbf{0 . 5 7} \\
0.81\end{array}$ & $\begin{array}{l}\mathbf{0 . 7 5} \\
0.83 \\
\mathbf{0 . 5 3} \\
0.82 \\
\mathbf{0 . 6 2} \\
0.83\end{array}$ & $\begin{array}{l}\mathbf{0 . 8 2} \\
0.91 \\
\mathbf{0 . 6 8} \\
0.89 \\
\mathbf{0 . 7 8} \\
0.91\end{array}$ & $\begin{array}{l}\mathbf{0 . 9 4} \\
0.98 \\
\mathbf{0 . 8 4} \\
0.96 \\
\mathbf{0 . 8 9} \\
0.96\end{array}$ \\
\hline Alps/Jura & \multicolumn{4}{|c|}{ Validation on Jura $(\mathrm{N}=222)$} \\
\hline Model & Kappa_05 & Kappa_opt & CCR_05 & AUC \\
\hline $\begin{array}{l}\text { Pre-Alps } \\
\text { Alps } \\
\text { Jura } \\
\text { Pre-Alps/Alps } \\
\text { Pre-Alps/Jura } \\
\text { Alps/Jura }\end{array}$ & $\begin{array}{l}\mathbf{0 . 5 7} \\
\mathbf{0 . 4 2} \\
0.86 \\
\mathbf{0 . 6 0} \\
0.77 \\
0.74\end{array}$ & $\begin{array}{l}\mathbf{0 . 7 2} \\
\mathbf{0 . 4 8} \\
0.88 \\
\mathbf{0 . 6 2} \\
0.81 \\
0.74\end{array}$ & $\begin{array}{l}\mathbf{0 . 7 7} \\
\mathbf{0 . 7 4} \\
0.93 \\
\mathbf{0 . 8 0} \\
0.89 \\
0.88\end{array}$ & $\begin{array}{l}\mathbf{0 . 9 4} \\
\mathbf{0 . 8 3} \\
0.99 \\
\mathbf{0 . 9 1} \\
0.98 \\
0.95\end{array}$ \\
\hline
\end{tabular}

graphy) capercaillie avoid valley bottoms and preferably inhabit ridges and upper slopes. This could be explained 1) by ridges and upper slopes having better habitat quality or 2) by predator-avoidance behaviour. Capercaillie disturbed by predators or humans tend to escape downhill (own observations), where they need habitat

Table 4. Variables in the multivariate capercaillie habitat models built with data from one region (Pre-Alps, Alps, Jura) and with pooled data from two regions (Pre-Alps/Alps, Pre-Alps/Jura, Alps/Jura); spatial grain size used for each variable (Scale [ha]); type of response, i.e. linear positive (pos) or linear negative (neg); level of significance (***: p-value $<0.001, * *: 0.01>\mathrm{p}>0.001$, $*: 0.1>\mathrm{p}>0.01)$.

\begin{tabular}{|c|c|c|c|c|c|c|c|c|c|}
\hline \multirow[b]{2}{*}{ Variable } & \multicolumn{3}{|c|}{ Pre-Alps } & \multicolumn{3}{|c|}{ Alps } & \multicolumn{3}{|c|}{ Jura } \\
\hline & Scale & Response & Sig. & Scale & Response & Sig. & Scale & Response & Sig. \\
\hline PFOR & 253 & pos & $* * *$ & 81 & pos & $* * *$ & 1129 & pos & $* * *$ \\
\hline TAVE & 1 & pos & $*$ & 1 & neg & $* * *$ & 1 & pos & \\
\hline TAVE $^{2}$ & 1 & neg & $*$ & 1 & neg & & 1 & neg & $* * *$ \\
\hline TOPO & 1129 & pos & & 5 & pos & $*$ & 113 & neg & \\
\hline
\end{tabular}

\begin{tabular}{|c|c|c|c|c|c|c|c|c|c|}
\hline \multirow[b]{2}{*}{ Variable } & \multicolumn{3}{|c|}{ Pre-Alps/Alps } & \multicolumn{3}{|c|}{ Pre-Alps/Jura } & \multicolumn{3}{|c|}{ Alps/Jura } \\
\hline & Scale & Response & Sig. & Scale & Response & Sig. & Scale & Response & Sig. \\
\hline PFOR & 253 & pos & $* * *$ & 529 & pos & $* * *$ & 113 & pos & $* * *$ \\
\hline TAVE & 1 & pos & $* * *$ & 1 & pos & $* *$ & 1 & pos & $* * *$ \\
\hline TAVE $^{2}$ & 1 & neg & $* * *$ & 1 & neg & $* * *$ & 1 & neg & $* * *$ \\
\hline TOPO & 5 & pos & $* *$ & 1129 & pos & & 29 & pos & $* * *$ \\
\hline
\end{tabular}


suitable for landing, hiding, and from where they can safely walk back.

We used only three environmental variables in this study to ensure a maximum comparability of the different habitat models. To include a number of variables that describe local conditions could have masked the effect of the geographic extent of the calibration data on model generality. We are well aware that important habitat factors are not included in the analysis, such as canopy cover (e.g. Storch 1993b, Suchant 2002, Sachot et al. 2003) or field layer (e.g. Schroth 1992, Bollmann et al. 2005).

\section{Model precision versus generality}

Before evaluating the generality of our models we address the role of different accuracy measures to assess model performance on validation data. Threshold-dependent accuracy measures are believed to be inferior to AUC, which provides a threshold-independent measure of accuracy (Guisan and Zimmermann 2000). In our case, all models attained an AUC $\geq 0.8$ when applied outside the calibration area, and thus have excellent predictive value (cf. Hosmer and Lemeshow 2000). Consequently, all models (regional and pooled models) seem to possess high generality. However, if habitat models are used in conservation practice quite often a particular threshold has to be applied to make spatially explicit predictions for presence-absence. Such predictions can, for instance, be included in a Species Action Plan. Further, if a habitat model has to be applied outside its calibration area with no or only sparse data on species distribution, the threshold can not be optimized. Therefore, we believe that Kappa_05 is a very important measure of model accuracy, especially if the focus of a study is on model generality. In our study, the minimum value of Kappa_05 for the regional models was 0.26 indicating a poor prediction (cf. Monserud and Leemans 1992). By contrast, the models built with pooled data from two regions predicted moderately well to well. Thus, applying pooled models reduces the probability of coming up with poor predictions outside the calibration region.

Though not surprising, it is still noteworthy that three reasons may be responsible for the differences in model performance. First, if species-habitat relationships are influenced by regional conditions, generality of a model will be higher with increasing variation in the data used for calibration (see Dettmers et al. 2002). This is supported by our finding that using pooled data from two regions (and thus increasing variation in calibration data) increases the predictive success of the model outside its calibration region. Second, models were successful in predicting species distribution in distinct, independent regions if these new regions are ecologically similar with respect to the predictor variables (Rodriguez and Andren 1999, Morris et al. 2001, Whittingham et al. 2003). In our case, the central Alps differ more from the two other regions than the Pre-Alps differ from the Jura Mountains. As a consequence, lowest accuracy values were attained by the regional Alpine model tested on the other two regions and by the regional models built with data from the Pre-Alps and the Jura tested on data from the Alps. Third, generality of a model depends on the degree to which the predictor variables have direct ecological significance, as opposed to being surrogate variables (Guisan and Zimmermann 2000). This important aspect will be discussed separately in the next paragraph.

\section{Causality versus correlation}

The loss of predictive power when a habitat distribution model is applied in a distinct region has two major reasons. First, species-habitat relationships may vary significantly between regions (Wiens et al. 1987, Fielding and Haworth 1995). This part of the loss of predictive power can not be reduced by using better predictor variables. Second, indirect variables may lower the generality of habitat distribution models (Guisan and Zimmermann 2000, Gibson et al. 2004), because association of such variables to the direct habitat factors and thus to the species occurrence may differ between regions. Therefore, it is desirable to predict the distribution of a species on the basis of ecological parameters that are assumed to be the causal (direct) driving forces for its distribution and abundance (Guisan and Zimmermann 2000). Such direct variables are often not (yet) available consistently over large areas, and this leads to a common dilemma in conservation biology: spatially explicit concepts or guidelines for solving conservation problems are often required immediately. Consequently, there is not enough time available for a systematic data assessment. Therefore, it is important to investigate the power and limitations of large-scale habitat distribution models that are at least partly based on indirect predictor variables. Our models predicted the large-scale pattern of capercaillie presence-absence well in the calibration region and the models built with pooled data from two regions performed fairly well on independent data from a spatially separated, ecologically distinct region. Thus, the predictors we used must at least partly have a direct effect on capercaillie occurrence.

\section{Conclusions}

The results of this study support earlier warnings that caution is required when habitat distribution models are applied in other geographical regions. The relationship 
of species occurrence to a predictor variable can differ in its direction and strength. Indirect variables can be problematic in that they reduce the applicability of the model to larger geographical extents. Applying models can thus lead to poor predictions if the region where the model is applied differs ecologically from the calibration region. We circumvented these problems by building habitat models with data pooled from two regions that were different with respect to climate, topography, forest distribution patterns and tree species composition. This approach produced models of higher generality without loosing much precision when applied in the individual regions. Our models with pooled data therefore meet the prerequisites for predictive models to be useful as conservation and management tools. We recommend testing our pooling approach for its general usefulness with other animal species and habitats.

Acknowledgements - This study received financial support from the Swiss National Science Foundation (SNF; grant number 3100-065199) and the Swiss Agency for the Environment, Forests and Landscape (BUWAL). The Swiss Ornithological Inst. (P. Mollet), Ecotec Environnement SA and several regional grouse experts (B. Badilatti, R. Hess, F. Rudmann, and others) provided large data-sets on capercaillie occurrence. We thank U. Rehsteiner and D. Thiel for assistance in the field and N. E. Zimmermann for letting us have processed environmental data. We are grateful to A. Guisan for comments on an earlier version of this manuscript.

\section{References}

Baines, D., Moss, R. and Dugan, D. 2004. Capercaillie breeding success in relation to forest habitat and predator abundance. - J. Appl. Ecol. 41: 59-71.

Bollmann, K., Weibel, P. and Graf, R. F. 2005. An analysis of central Alpine capercaillie spring habitat at the forest stand scale. - For. Ecol. Manage. 215: 307-318.

Boyce, M. S. et al. 2002. Evaluating resource selection functions. - Ecol. Modell. 157: 281-300.

Carroll, C., Zielinski, W. J. and Noss, R. F. 1999. Using presence-absence data to build and test spatial habitat models for the fisher in the Klamath region, USA. - Conserv. Biol. 13: 1344-1359.

Corsi, F., Dupre, E. and Boitani, L. 1999. A large scale model of wolf distribution in Italy for conservation planning. - Conserv. Biol. 13: 150-159.

Cushman, S. A. and McGarigal, K. 2004. Patterns in the species-environment relationship depend on both scale and choice of response variables. - Oikos 105: 117-124.

Deleo, J. M. 1993. Receiver operating characteristic laboratory (ROCLAB): software for developing decision strategies that account for uncertainty.. - In: First international symposium on uncertainty modelling and analysis. - IEEE Computer Society Press.

Dettmers, R., Buehler, D. A. and Bartlett, J. B. 2002. A test and comparison of wildlife-habitat modeling techniques for predicting bird occurrence at a regional scale. - In: Scott, J. M. et al. (eds), Predicting species occurrences - issues of accuracy and scale. Island Press, pp. 607-615.

Eiberle, K. 1976. Zur Analyse eines Auerwildbiotopes im Schweizerischen Mittelland. - Forstw. Cent.bl. 95: 108-124.

Fielding, A. H. and Haworth, P. F. 1995. Testing the generality of bird-habitat models. - Conserv. Biol. 9: 1466-1481.
Fielding, A. H. and Bell, J. F. 1997. A review of methods for the assessment of prediction errors in conservation presence/ absence models. - Environ. Conserv. 24: 38-49.

Gibson, D. J. et al. 2004. Spatial prediction of rufous bristlebird habitat in a coastal heathland: a GIS-based approach. - J. Appl. Ecol. 41: 213-223.

Gjerde, I. 1991. Cues in winter habitat selection by capercaillie. I. Habitat characteristics. - Ornis Scand. 22: 197-204.

Graf, R. F. 2005. Analysis of capercaillie habitat at the landscape scale using aerial photographs and GIS. - Ph.D. thesis, Swiss Federal Inst. of Technology, Zürich.

Graf, R. F. et al. 2005. The importance of spatial scale in habitat models: capercaillie in the Swiss Alps. - Landscape Ecol. 20: $703-717$.

Guisan, A. and Zimmermann, N. E. 2000. Predictive habitat distribution models in ecology. - Ecol. Modell. 135: 147186.

Guisan, A., Weiss, S. B. and Weiss, A. D. 1999. GLM versus CCA spatial modeling of plant species distribution. - Plant Ecol. 143: 107-122.

Hosmer, D. W. and Lemeshow, S. 2000. Applied logistic regression. - Wiley.

Ihaka, R. and Gentleman, R. 1996. R: a language for data analysis and graphics. - J. Comput. Graph. Stat. 5: 299314.

Keppie, D. M. and Kierstead, J. M. 2003. The need to improve our attention to scale of resolution in grouse research. - Wildl. Biol. 9: 385-391.

Klaus, S. et al. 1985. Zur Ökologie des Auerhuhns (Tetrao urogallus L.) in Thüringen. - Acta Ornithoecol. 1: 3-46.

Klaus, S. et al. 1986. Die Auerhühner. - A. Ziemsen.

Kurki, S. et al. 2000. Landscape fragmentation and forest composition effects on grouse breeding success in boreal forests. - Ecology 81: 1985-1997.

Lawler, J. J. and Edwards, T. C., Jr 2002. Landscape patterns as habitat predictors: building and testing models for cavitynesting birds in the Uinta Mountains of Utah, USA. - Landscape Ecol. 17: 233-245.

Leclercq, B. 1987. Influence de quelques pratiques sylvicoles sur la qualité des biotopes à Grand Tétras (Tetrao urogallus) dans le massif du Jura. - Acta Oecol. 2: 237-246.

Linden, H. et al. 2000. Large-scale forest corridors to connect the taiga fauna to Fennoscandia. - Wildl. Biol. 6: 179-188.

Mace, R. D. et al. 1999. Landscape evaluation of grizzly bear habitat in western Montana. - Conserv. Biol. 13: 367-377.

Manel, S., Dias, J. M. and Ormerod, S. J. 1999. Comparing discriminant analysis, neural networks and logistic regression for predicting species distributions: a case study with a Himalayan river bird. - Ecol. Modell. 120: 337-347.

Manly, B. F. J. et al. 2002. Resource selection by animals - statistical design and analysis for field studies. - Kluwer.

McPherson, J. M., Jetz, W. and Rogers, D. J. 2004. The effects of species' range sizes on the accuracy of distribution models: ecological phenomenon or statistical artefact? - J. Appl. Ecol. 41: 811-823.

Menard, S. 2002. Applied logistic regression analysis. - Sage Publ.

Mladenoff, D. J. and Sickley, T. A. 1998. Assessing potential gray wolf restoration in the northeastern United States: a spatial prediction of favorable habitat and potential population levels. - J. Wildl. Manage. 62: 1-10.

Mollet, P. et al. 2003. Verbreitung und Bestand des Auerhuhns Tetrao urogallus in der Schweiz 2001 und ihre Veränderungen im 19. und 20. Jahrhundert. - Ornithol. Beob. 100: 6786.

Monserud, R. A. and Leemans, R. 1992. Comparing global vegetation maps with the Kappa statistics. - Ecol. Modell. 62: $275-293$.

Morris, A. J. et al. 2001. Foraging habitat selection by yellowhammers (Emberiza citrinella) nesting in agriculturally contrasting regions in lowland England. - Biol. Conserv. 101: $197-210$. 
Moss, R., Oswald, J. and Baines, D. 2001. Climate change and breeding success: decline of the capercaillie in Scotland. - J. Anim. Ecol. 70: 47-61.

Nagelkerke, N. J. D. 1991. A note on a general definition of the coefficient of determination. - Biometrika 78: 691-692.

Picozzi, N. et al. 1992. Evaluation of capercaillie habitat. - J. Appl. Ecol. 29: 751-762.

Rodriguez, A. and Andren, H. 1999. A comparison of Eurasian red squirrel distribution in different fragmented landscapes. - J. Appl. Ecol. 36: 649-662.

Rolstad, J. 1988. Autumn habitat of capercaillie in southeastern Norway. - J. Wildl. Manage. 52: 747-753.

Rolstad, J. and Wegge, P. 1989. Capercaillie populations and modern forestry - a case for landscape ecological studies. - Finn. Game Res. 46: 43-52.

Rolstad, J., Wegge, P. and Larsen, B. B. 1988. Spacing and habitat use of capercaillie during summer. - Can. J. Zool. 66: $670-679$.

Roth, P. and Nievergelt, B. 1975. Die Standorte der Balzplätze beim Auerhuhn (Tetrao urogallus). - Ornithol. Beob. 72: $101-112$.

Rushton, S. P., Ormerod, S. J. and Kerby, G. 2004. New paradigms for modelling species distributions? - J. Appl. Ecol. 41: 193-200.

Sachot, S. 2002. Viability and management of an endangered capercaillie (Tetrao urogallus) metapopulation. - Ph.D. thesis, Univ. of Lausanne.

Sachot, S. and Perrin, N. 2004. Capercaillie (Tetrao urogallus) in western Switzerland - viability and management of an endangered grouse metapopulation. - In: Akcakaya, H. R. et al. (eds), Species conservation and management: case studies. Oxford Univ. Press, pp. 384-396.

Sachot, S., Perrin, N. and Neet, C. 2003. Winter habitat selection by two sympatric forest grouse in western Switzerland: implications for conservation. - Biol. Conserv. 112: 373-382.

Schroth, K.-E. 1992. Zum Lebensraum des Auerhuhns (Tetrao urogallus L.) im Nordschwarzwald. - Ph.D. thesis, Univ. of München.

Segelbacher, G., Storch, I. and Tomiuk, J. 2003. Genetic evidence of capercaillie Tetrao urogallus dispersal sources and sinks in the Alps. - Wildl. Biol. 9: 267-273.

Sharpe, P. J. A. 1990. Forest modeling approaches: compromises between generality and precision. - In: Dixon, R. K. et al. (eds), Process modeling of forest growth responses to envrionmental stress. Timber Press, pp. 180-190.

Sjöberg, K. 1996. Modern forestry and the capercaillie. - In: DeGraaf, M. and Miller, R. I. (eds), Conservation of faunal diversity in forested landscapes. Chapman and Hall, pp. $111-135$.

Storch, I. 1993a. Habitat selection by capercaillie in summer and autumn - is bilberry important? - Oecologia 95: 257265.

Storch, I. 1993b. Patterns and strategies of winter habitat selection in alpine capercaillie. - Ecography 16: 351-359.

Storch, I. 1994. Habitat and survival of capercaillie Tetrao urogallus nests and broods in the bavarian alps. - Biol. Conserv. 70: 237-243.
Storch, I. 1995. Annual home ranges and spacing patterns of capercaillie in central Europe. - J. Wildl. Manage. 59: $392-$ 400 .

Storch, I. 1997. The importance of scale in habitat conservation for an endangered species: the capercaillie in central Europe. - In: Bissonette, J. A. (ed.), Wildlife and landscape ecology: effects of pattern and scale. Springer, pp. 310-330.

Storch, I. 2000a. Conservation status and threats to grouse worldwide: an overview. - Wildl. Biol. 6: 195-204.

Storch, I. (ed.) 2000b. Grouse status survey and Conservation Action Plan 2000-2004. -WPA/BirdLife/SSC Grouse Specialist Group. IUCN, Gland, Switzerland and Cambridge, UK and the World Pheasant Association, Reading, UK.

Storch, I. 2002. On spatial resolution in habitat models: can small-scale forest structure explain capercaillie numbers? - Conserv. Ecol. 6: 6 [online] URL: <http://www.consecol. org/vol6/iss 1/art6 $>$.

Storch, I. and Segelbacher, G. 2000. Genetic correlates of spatial population structure in central European capercaillie Tetrao urogallus and black grouse T. tetrix: a project in progress. - Wildl. Biol. 6: 305-310.

Suchant, R. 2002. Die Entwicklung eines mehrdimensionalen Habitatmodells für Auerhuhnareale (Tetrao urogallus L.) als Grundlage für die Integration von Diversität in die Waldbaupraxis. - Ph.D. thesis, Univ. Freiburg.

Summers, R. W. et al. 2004. An experimental study of the effects of predation on the breeding productivity of capercaillie and black grouse. - J. Appl. Ecol. 41: 513-525.

Wegge, P. and Rolstad, J. 1986. Size and spacing of capercaillie leks in relation to social behaviour and habitat. - Behav. Ecol. Sociobiol. 19: 401-408.

Wegge, P. and Larsen, B. B. 1987. Spacing of adult and subadult male common capercaillie during the breeding season. - Auk 104: 481-490.

Wegge, P., Rolstad, J. and Gjerde, I. 1992. Effects of boreal forest fragmentation on capercaillie grouse: empirical evidence and management implications. - In: McCullough, D. R. B. R. H. (ed.), Wildlife 2001: populations. Elsevier, pp. 738-749.

Whittingham, M. J., Wilson, J. D. and Donald, P. F. 2003. Do habitat association models have any generality? Predicting skylark Alauda arvensis abundance in different regions of southern England. - Ecography 26: 521-531.

Wiens, J. A., Rotenberry, J. T. and Vanhorne, B. 1987. Habitat occupancy patterns of north-american shrubsteppe birds - the effects of spatial scale. - Oikos 48: 132-147.

Zabel, C. J. et al. 2003. Northern spotted owl habitat models for research and management application in California (USA). - Ecol. Appl. 13: 1027-1040.

Zimmermann, N. E. and Kienast, F. 1999. Predictive mapping of alpine grasslands in Switzerland: species versus community approach. - J. Veg. Sci. 10: 469-482.

Zimmermann, N. E. and Roberts, D. W. 2001. Final report of the MLP climate and biophysical mapping project. - Swiss Federal Research Inst. WSL, Birmensdorf, Switzerland and Utah State Univ., Logan, USA. 